\title{
EL MÉTODO BIOGRÁFICO NARRATIVO APLICADO A LOS BIENES CULTURALES. Una experiencia inclusiva e intercultural en la GAMeC.
}

\author{
THE BIOGRAPHICAL NARRATIVE METHOD APPLIED TO THE CULTURAL OBJECTS. \\ An inclusive and intercultural experience in the GAMeC.
}

\author{
Soledad Fernández-Inglés \\ Universidad de Málaga, España. \\ sfernandezingles@uma.es \\ https://orcid.org/0000-0002-5926-1876 \\ Rosario Gutiérrez-Pérez \\ Universidad de Málaga, España. \\ mrgutierrezp@uma.es \\ https://orcid.org/oooo-0003-4520-363X
}

$\begin{array}{llll}\text { Recibido } & 14 / 01 / 2018 & \text { Revisado } & 19 / 04 / 2018 \\ \text { Aceptado } & 13 / 05 / 2018 & \text { Publicado } & 01 / 07 / 2018\end{array}$

\section{Resumen}

La narración no es solo un género literario: se encuentra en la Paleontología, la Historia, la Psicología, la Pedagogía, en el Derecho, en el discurso científico. Es algo verdaderamente amplio. Ciencia y Arte han cooperado en la experimentación del discurso narrativo sobre qué supone narrar, el lenguaje y la percepción en la capacidad de transformar y transformarse del ser humano.

La narrativa museal está entrando de lleno en algunos museos como medio de acercamiento a la obra de arte. Con detractores y defensores se abre camino de forma tímida, aunque aún no sabemos qué recorrido tendrá en el tiempo. En este

\section{Abstract}

The narrative is not just a literary genre: it is found in Paleontology, History, Psychology, Pedagogy, Law, in scientific discourse. It is truly broad. Science and Art have cooperated in the experimentation of the narrative discourse on what it means to narrate, language and perception in the capacity to transform and transform the human being.

The museal narrative is entering fully into some museums as a mean of approaching the work of art. With detractors and defenders, the road opens up timidly, although we still do not know what route it will take in time. In this area, the Galleria d'Arte Moderna e Contemporanea (GAMeC) of Bergamo

Para citar este artículo

Fernández-Inglés, Soledad. \& Gutiérrez-Pérez, Rosario (2018). El método biográfico narrativo aplicado a los bienes culturales. Una experiencia inclusiva e intercultural en la GAMeC. Tercio Creciente, 14, págs. 7-16. https://dx.doi.org/10.17561/rtc.n14.1 
ámbito trabaja desde 2007 la Galleria d'Arte Moderna e Contemporanea (GAMeC) de Bergamo, que lo ha adaptado como herramienta de los Servicios Educativos en su política de desarrollo y de inclusión social y cultural. has been working since 2007, which has adapted it as a tool for educational services in its development and social and cultural inclusion policy.

Palabras clave / Keywords

Narración, autobiografía, museo, patrimonio, inclusión.

Narration, autobiography, museum, heritage, inclusion.

Para citar este artículo

Fernández-Inglés, Soledad. \& Gutiérrez-Pérez , Rosario (2018). El método biográfico narrativo aplicado a los bienes culturales. Una experiencia inclusiva e intercultural en la GAMeC. Tercio Creciente, 14, págs. 7-16. https://dx.doi.org/10.17561/rtc.n14.1 


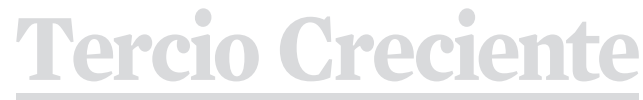

ISSN: 2340-9096

DOI: https://dx.doi.org/10.17561/rtc.n14.1

\section{Introducción}

Cuando hablamos de narración hablamos de conocer; quien narra sabe algo pero también "hace saber". El problema lo tenemos cuando buscamos la etimología de otra palabra que es sinónima: contar. ¿Qué tiene que ver contar con contar-narrar? En italiano se distingue muy bien porque diferencia contare de raccontare. El racconto es cualitativo, el contare cuantitativo. Tienen en común el interés por referir algo que se relaciona con la realidad; sea contare que raccontare se asocian con el cuerpo, con una comunicación no verbal; ambas tienen que ver con la palabra computare, que en latín significar leer y procede de puto, y con legens. recoger, reunir, pero también contar, calcular, enumerar. Con este término seleccionamos una parte de la realidad; con raccontare cosas específicas. Se trata de significados interesantes que unen contare/raccontare con leer la escritura. Nosotros hablamos de narrar.

Narramos lo que recordamos. El problema al que tenemos que hacer frente es qué es lo que narramos. Hacemos uso de la memoria pero nos hallamos ante un problema: la diversidad sobre cómo pienso o recuerdo en relación a cómo lo cuento. El modo en que decimos las cosas depende de variables particulares supeditadas a un orden (Smorti, 2001, p.58). El lenguaje inserta un orden que tiene que ver con lo que vemos y sentimos, que depende de nuestro estado de ánimo; por este motivo, las confesiones están ligadas en cierto modo: cuento para transformarme. El género autobiográfico está construido buscando demostrar la diversidad, pero hay que encontrar la explicacion ligada al cambio.

\section{El método autobiográfico en la transformación del ser humano}

La autobiografía parte de un presupuesto ligado al hecho que cuento mi vida partiendo desde un punto cero. Cuando la cuento, lo hago como si no supiera lo que después pasará, como si fuera un sujeto ingenuo de mi propia vida. Al escribir las cosas ya las se, y así se funda sobre este aparente conflicto entre un personaje que no sabe nada y un narrador que lo sabe todo. Esta aparente conflictualidad determina una serie de presuposiciones que, a menudo, están dentro de ser conscientes de por qué las cosas han ocurrido de ese modo; pero necesito explicarlas. Rousseau decía que una persona es plenamente consciente de quién es desde el momento en que cuenta de sí misma.

La autobiografía es una teoría sobre nosotros mismos. Tiene una característica principal: tomar un personaje y llevarlo a un lugar determinado. Bruner (2001, p.27) dice que el deber de un narrador es el de conducir al protagonista del pasado al presente, de manera que ambos sean una sola persona con una consciencia común. Así contamos episodios de nuestra vida.

El fin de la narracion autobiografica tiene que ver con el sentido que queremos darle a lo que contamos. La estructura tipica de las narraciones son evidenciadas y caracterizadas por situaciones que crean excepcionalidad, problemas que se diferencian de lo que resulta exclusivo; es decir: no contamos hechos que no son excepcionales, sino que lo son en relación al modo en que se desarrollan los 
eventos y, en virtud de ello, merecen ser contados "en el momento justo y con los recursos apropiados" (Smorti, 2001, p.61).

Dicho todo ello ¿qué diferencia hay entre autobiografía y narración? La primera tiene una estructura cristalizada y presenta además la característica de ser una teoría sobre uno mismo. Los episodios narrativos tienen una estructura fluida, dependen del contexto y tienen el fin de comprender un determinado evento acaecido. No sabemos si se puede decir que sabemos todo, porque podemos tener dudas sobre lo que ha pasado y porque cada uno tiene su propia narración autobiográfica.

\section{Procesos para construir historias. Memoria y narración}

¿Cómo se transforma una narración en historia? Andrea Smorti (2001) indica que es una transformación que requiere pasar por dos procesos: el de externalización y el de narrativización. Cuando hablamos externalizamos nuestros recuerdos. Posteriormente tiene lugar un segundo proceso - lo que Smorti llama narrativización - ya que en cada historia hay tres aspectos que van siempre considerados: primero, la fabula o texto; segundo, el modo en el que articulamos y justificamos el texto; $y$, tercero, el contexto; es decir, que decimos, cómo, por qué y a quién. Estos elementos nos permiten producir historias desde las que establecemos vínculos. Cuando tienen el formato de narración cuentan con estas características, de forma que cualquiera de nosotros puede elaborar expectativas sobre las historias porque las hemos oido muchas veces. En este sentido disponemos de lo que se conoce como "esquema de relato", que nos dice cómo comunmente está construido (pp.66-69); así, en la producción de una historia, estamos dotados de una serie de suposiciones ligadas a este esquema que condicionan su interpretación, y en la que entra en juego el factor "valoraciones". Este factor consiste en "todos aquellos medios que el narrador utiliza para indicar el punto central de la narración, su razón de ser: por qué la historia es narrada y qué había previsto realizar el narrador" (Labov, 1972 citado en Smorti, 2001, p.61), creando expectativas.

$Y$ aquí entra la memoria: Desde el momento en que partimos de ella, para continuar en la racionalización de lo que recordamos, entramos en un momento colectivo, en episodios que son comunes a la historia de muchos al ser sucesos acaecidos durante un tiempo y en un lugar determinado (por ejemplo, un episodio traumático, como el atentado a las Torres Gemelas, u otro esperanzador, como la caída del muro de Berlín). La memoria no es solamente huella, sino recuerdo de esas huellas (Changeux, 2002, p.19). Los malos recuerdos tienden a ser recordados con mayor profusión que los positivos porque tienen que ser reelaborados continuamente para superarlos; en este sentido, cuanto más parecido es un evento a otro mayor mayor es su tendecia a desaparecer.

¿Cómo se mantienen en vida los recuerdos? Insertados progresivamente en estructuras más amplias, por lo que suponemos que podemos mezclarlos con otras situaciones creadas como eventos específicos. Muchos de estos recuerdos los contamos recurriendo a la memoria. Cuando nos contamos lo hacemos entre memoria y narración y dotando a nuestra historia de una naturaleza social porque siempre nos contamos a alguien. Al narrar estamos transformando una actividad individual en otra social, porque la memoria se comparte: el recuerdo de uno es ofrecido al otro y el otro lo recibe (Ricoeur, 2002, p.27). La narracion de nosotros mismos necesita ser plausible e interesante. Plausible porque debe ser clara, creíble; interesante porque, de no ser así, nadie nos escucharía. En el momento en que debemos contar algo plausible e interesante, el recuerdo tiene que ser transformado en virtud a esta exigencia social; lo que pasa es que transformamos los recuerdos en funcion de la narración y de las personas a quienes va dirigida. Así, la narracion: transforma la memoria en sentido lineal, serial; filtra las experiencias a través del 


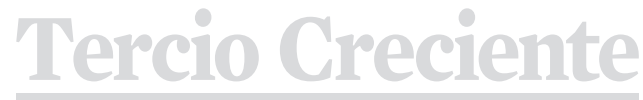

ISSN: 2340-9096

DOI: https://dx.doi.org/10.17561/rtc.n14.1 lenguaje, las traduce en lo que Slobin (1996) llama "eventos verbalizados", que se construyen on line en el momento de hablar (p.75) y suponen un potente modo de llamar y dar vida a una historia. A diferencia de ser, "acordarse de contar" significa hablar siempre a alguien, y preocuparnos de hacerlo de manera sugerente; de ahí que sufra transformaciones relevantes. Son experiencias filtradas a través del lenguaje.

\footnotetext{
"Parece evidente, entonces, que la habilidad para construir narraciones y para entender narraciones es crucial en la construcción de nuestras vidas y la construcción de un 'lugar' para nosotros mismos en el posible mundo al que nos enfrentamos" (Bruner, 1999, p. 59).
}

\section{Un patrimonio de historias para la narrativa museal}

En la filtración de las experiencias, base de lo que los Servicios Educativos de la GAMeC denominan narrativa museal, situamos "un patrimonio de historias", método que favorece la inclusión social a partir del conocimiento de sí mismo. Se trata de recordar un evento, magnificado por la lejanía, que lleva a tomar conciencia de la propia identidad; por eso, a menudo, lo que estoy contando es la historia de una historia de la historia. "El arte nos muestra lo que es o lo que podría ser la vida" (Smorti, 2001, p.30). Una obra de arte puede ser un espejo donde mirarnos porque el arte necesita contarse, dar voz a la experiencia educativa y estética, siempre que sea voz también de la experiencia ética. En él se refleja la conciencia colectiva, para la que lo que cuenta no son los hechos recientes y experimentados de manera directa, sino comunicar experiencias que es donde reside la capacidad de contar. Walter Benjamin dice que si perdemos esta capacidad perdemos también la de compartir experiencias (Benjamin, 2001, pp. 121-124). En la obra de arte, como en los textos, los conocimientos se comunican con mayor facilidad porque su presencia cobra en ella mayor relieve (de Romilly, 2002, p.46).

La narración en clave autobiográfica es un instrumento que no solo se compenetra con la mediación para la comprensión del patrimonio en un código intercultural, sino que es un recurso fundamental para la ciudadanía activa, para la alfabetización crítica en la edad adulta y para la creación del sentido de pertenencia a un lugar. Se trata pues de una herramienta que ha pasado a formar parte de las políticas de desarrollo y de inclusión social y cultural de los servicios educativos de la Galleria d'Arte Moderna e Contemporanea (GAMeC) de Bergamo desde 2007. Otros museos, como la Pinacoteca de Brera, la Accademia Carrara de Bergamo, el Museo del Cinema de Torino y el Museo Nazionale Preistorico Etnografico Pigorini de Roma, lo han adoptado como paradigma para trabajar con las obras y sobre las obras artísticas, promoviendo el conocimiento del arte y la inclusión social y cultural.

En Italia, el mediador cultural suele ser un extranjero residente en este país, que puede tener o no ciudadanía italiana. Normalmente es una figura que sirve de enlace entre los diferentes organismos del Estado y el inmigrante, ayudando en la resolución de problemas burocráticos y de acercamiento a las estructuras sociales, culturales, sanitarias, y educativas. A partir de 2007, los Servicios Educativos de la GAMeC formaron un grupo de treinta y tres mediadores provenientes de diferentes países para instruirlos en competencias artísticas y culturales del museo. Durante la colaboración con el Teatro Donizetti en el proyecto "Tracce straniere", promovió un bando dirigido a ciudadanos inmigrantes de Bergamo y provincia para activar un curso de formación de mediadores museales. En el transcurso de estos años no solo se han convertido en guías de lengua materna para inmigrantes y turistas, sino en pieza del engranaje en proyectos interculturales y seminarios de alta formación para estudiantes 


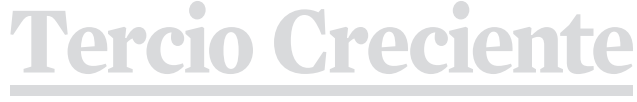

ISSN: 2340-9096

DOI: https://dx.doi.org/10.17561/rtc.n14.1
Revista de Estudios en Sociedad,

Artes y Gestión Cultural

wwwterciocrecientecom

http://revistaselectronicas.ujaen.es/index.php/RTC universitarios, cursos de actualización para docentes y cursos de accesibilidad para personas con discapacidad funcional y/o en situación de desarraigo social.

En 2014, la GAMeC puso en pie un proyecto al que llamaron "12 narratori in cerca d'autore", en el ámbito del cual se ha creado un cruce entre la colección permanente, el patrimonio cultural inmaterial (memoria y tradición) y la identidad cultural. Su misión es la de dar vida a una narración que se transforme en puente, y salga de la óptica del historiador del arte para entrar en la del hombre.

La narración en clave autobiográfica da voz a los objetos y a sus autores en diálogo con la vida de las personas, creando sentimientos de empatía. Es hacer museo y educar al patrimonio utilizando la capacidad de transformar que hay implícita en la narración de los mediadores museales, quienes ponen en juego emociones que nacen y pertenecen a recuerdos nacidos en otros contextos geográficos que traen a la memoria, a veces magnificándolos y otras utilizándolos para sanar o mejorar la vida a través de ellos. Además, "como producto resultante de una determinada cultura, constituye una importante fuente de conocimiento y al mismo tiempo de la educación y de valores de la cultura que le son propios". (Smorti, 2001, p. 64)

En la construcción de este proyecto, Silvia Mascheroni, Simona Bodo y Maria Grazia Panigada, junto a Emanuela Daffra, Giovanna Brambilla y otros, siempre han tenido en cuenta quién, a quién y a través de qué se dirigen. No trabajan por comunidades sino con grupos heterogéneos que incluyen diferentes nacionalidades. Salvaguardando los contenidos, pero entrelazándolos con la vida cotidiana, surgen posibles lecturas transversales de modo que el museo se convierte en un lugar para reflexionar. El método narrativo funciona en grupo, y éste funciona como una caja de resonancia. Al inicio del epígrafe decíamos que otros museos lo han adoptado como paradigma, pero cada realidad es diferente por lo que es un proyecto que se va reconstruyendo según el lugar. Museo y patrimonio pero también territorio son así las piezas claves.

Todos tenemos un patrimonio personal, un cúmulo de vivencias que han ido marcando nuestra vida y que guardamos en forma de objetos, de recuerdos o de sus representaciones (...). Un pequeño acervo que cuando se comparte en sus significados con el grupo humano de la familia configura el patrimonio familiar. Es por ello que enfatizo la idea de 'compartir significados' porque no es patrimonio cultural la mera acumulación de los bienes patrimoniales de cada uno de los miembros que constituyen una familia, sino aquel conjunto de bienes con el que el colectivo familia se identifica. (Agirre, 2008, p.100)

Para Maria Grazia Panigada, la narración es el lapso de tiempo que transcurre entre que un hecho sucede hasta que lo contamos, mientras estamos elaborándolo en nuestra mente. Su trabajo en el museo consiste en valorar ese tiempo, convirtiéndolo en una narración que sienta sus bases en la necesidad de contar en relación al patrimonio, a la obra, que tiene que ver con lo qué queremos decir de ella; lo cautivador es que cada uno de nosotros nos unimos a nuestras imágenes a través de la narración. La dificultad del método autobiográfico-narrativo se halla en conseguir que el narrador se fie de sus propias historias. Narrar es un elemento fundamental de la relación humana: se narra por la necesidad y el deseo de comunicar lo vivido, los propios pensamientos y fantasías, y en sí es un elemento de contacto entre sensibilidades culturales diferentes. Bruner (2003) sostiene que contamos nuestra identidad teniendo siempre presente las expectativas de los demás, porque la narración del yo, por muy privada que parezca, es una cuestión pública; es decir, el yo es también del otro.

En la narración autobiográfica no es suficiente que se trate de una bonita historia sino que esté 


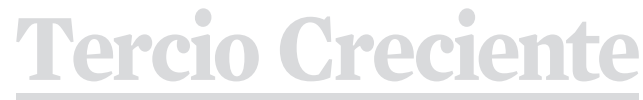

ISSN: 2340-9096

DOI: https://dx.doi.org/10.17561/rtc.n14.1
Investigación bien contada, y cada persona tiene su forma. Es la forma lo que Panigada tiene que ayudar a encontrar: en ella está presente la atención por el estudio histórico artístico de la obra, de su autor y época, elementos aportados por el histórico del arte que está siempre vigilante para que la narración con elementos autobiográficos se entrelace a la historia de la obra y de quien la ha creado. Este ha sido el papel de Emanuela Daffra y Paola Strada, quienes, como historiadoras del arte de GAMeC, han proporcionado materiales de lectura que han permitido releer las obras elegidas desde diferentes puntos de vista, "dejando espacio a un trabajo de búsqueda individual" (Panigada, 2016, p.60). Han sido ellas quienes han corregido los textos narrativos para que nada quedase fuera desde el punto de vista histórico artístico e hiciese creible cada narración en su diálogo con el museo.

Es muy importante la escucha para que se produzca un intercambio, por eso tiene que ser parte de un grupo compuesto por no más de quince, veinte personas, que desde hace años presta su competente servicio a la Pinacoteca. Los objetivos son siempre, primero, formar y experiementar una nueva forma de presentar las obras; segundo, crear mayor cohesión entre los mediadores, operación seguida de cerca por Simona Bodo y Silvia Mascheroni, expertas en educación al patrimonio en clave intercultural, cuya presencia es fundamental para crear un equilibrio en el proyecto de mediación de la colección, desde el principio hasta el momento de la exposición final. Lo más difícil es conseguir que el mediador se "deconstruya" de todos los saberes acumulados durante el tiempo que ha transcurrido formándose en el museo, para dejar aflorar las emociones de la experiencia humana. Para conseguirlo, optan por trabajar en talleres, lejos de las salas del museo, la propia percepción que tienen de sí los mediadores al ponerse en juego delante de los demás. Esto ha permitido a los autores del proyecto empezar a experimentar con un método narrativo que está muy lejos del tradicional y les ha dado la oportunidad de acercarse a los educadores involucrados, conocerles, comprender la especificidad expresiva que encierra cada una de las historias de vida presentes.

¿Cómo se realiza la elección de la obra? Para Panigada nunca es casual. Su trabajo consiste en acompañar al mediador durante este proceso, quien debe situarse delante de la obra el tiempo necesario, incluso semanas, para que ésta se vuelva familiar y "respire a través de ella". Si llega a ser importante para él o ella también lo será para los demás, por eso pide que reflexionen:

Spesso queste sono le domande: "scelgo l'opera che conosco meglio, di cui so parlare meglio, quella che nelle visite guidate vedo coinvolgere di più i visitatori? Evito a priori le opere "cult" del museo, perché rischierei troppo un giudizio di superficialità?" Entrambi questi criteri sono fuorvianti, perché seguendoli difficilmente si riesce a realizzare un intreccio con l'elemento autobiografico, se non, con evidenza, forzato. (Bodo, Mascheroni y Panigada, 2017, p. 62)

Según Maria Grazia Panigada, la elección que cada persona hace de la obra de arte tiene que ver con una relación profunda, bastante más de lo que parece al principio. A veces cambian la obra elegida y trabajada porque el resultado es demasiado racional, y se convierte más en un ejercicio de estilo que en una narración autobiográfica. Otras veces la elección es inmediata al encontrarse y fundirse el elemento autobiográfico con la materia histórico artística. Esto no quiere decir que se trate de un ejercicio terapéutico, aunque trabajar sobre una experiencia vivida a través del arte a menudo aporte beneficio personal. De lo que se trata es de buscar un instrumento que acerque el arte a aquellas personas que tienen dificultad para encontrar códigos que les permita descifrar las obras.

\section{Conclusiones}

En un mundo lleno de falsas posibilidades, la capacidad que tienen los objetos artísticos de 


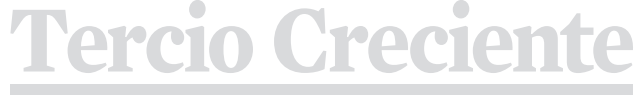

ISSN: 2340-9096

DOI: https://dx.doi.org/10.17561/rtc.n14.1 transmitir ideas, emociones y sentimiento sin que se agoten es una de las características que los define como arte. Contribuimos a ese proceso porque cada uno terminamos cada obra, cada artefacto artístico como queremos, llevándolo hacia el infinito. Las obras están ahí para inspirarnos, para ayudarnos a encontrar las piezas que terminen de construir y deconstruir el conocimiento de la realidad que nos rodea, aunque ésta sea múltiple y, por tanto, rebatible.

La realidad en la que nos movemos resulta cada vez más una construcción del ser humano; de ahí que los proyectos en museos nos muestren en muchas ocasiones la ideología elaborada que nos toca vivir y de la que no hay nada que decir, salvo que nos permita huir del adoctrinamiento. En este sentido, consideramos que los museos hace años que se han convertido en plataformas para las transmisión de ideas aprovechándose de la obra de arte, y creando en torno a ella discursos que olvidan los que le son propios. Por eso la iniciativa de $\mathrm{GAMeC}$, en la que la historiadora de arte - actuando como notaria - certifica que el discurso utilizado no violenta la obra ni la devalúa, sino que la abraza, nos parece tan meritoria. Los museos deben trabajar con las comunidades, lo que implica construir relaciones sociales. Trabajar con la comunidad en el museo y sobre el territorio, es un modo de limitar la imposición de cada nuevo sentido común creado por la política cultural de turno y de dar voz a todas y cada una de las diferencias expresadas por una sociedad multicultural.

Sin querer entrar en otros temas que nos llevarían a teorizar sobre la función del museo, solo añadimos que creemos en la necesidad de velar para que mantenga su función social sin permitir que sea consumido, usado en ocasiones de forma banal, utilizado como moneda de cambio para estudiantes, docentes y un público en general conducido, gracias a la desmotivación para considerar válidas las propias reflexiones tras la vivencia del hecho artístico. El museo solo pide ser el lugar donde la emoción y el pensamiento encuentren regocijo, donde el visitante entre con mente para construirse, corazón para sentir y ojos abiertos para sorprenderse.

\section{Cuando voy a visitar exposiciones o} museos, a veces "se me cae el alma" al observar a tanta gente que mira un cuadro como si observara al carnicero de la esquina cómo le pesa el kilo de chuletas, o cómo miran al semáforo cuando está en rojo. Verde, ámbar, rojo, tres colores de semáforo que se miran como señal para cruzar la calle; esa es la sensación que me dan muchos visitantes de exposiciones de arte... que pasan de un cuadro a otro y sólo han visto los colores del semáforo. (Jorge Rando, Málaga, enero de 2006 (día de Reyes). 
ISSN: 2340-9096

DOI: https://dx.doi.org/10.17561/rtc.n14.1

\section{Referencias}

Aguirre, I. (2008). Nuevas ideas de arte y cultura para nuevas perspectivas en la difusión del patrimonio. En V.V.A.A. El acceso al patrimonio cultural. Retos y Debates. (67-118), Pamplona: Universidad Pública de Navarra.

Benjamin, W. (2001). Para una crítica de la violencia y otros ensayos. Iluminaciones IV, Madrid: Taurus.

Bodo, S., Mascheroni, S. y Panigada, M.G. (2016). Un patrimonio di storie. La narrazione nei musei, una risorsa per la cittadinanza culturale, Milano: Mimesis.

Bruner, J. (1999). Actos de Significado: Más allá de la Revolución Cognitiva. Madrid: Alianza.

Bruner, J. (2001). La cultura dell'educazione: nuovi orizzonti per la scuola, trad.Lucia Cornalba. - 2. ed. -Milano: Feltrinelli.

Bruner, J. (2003). La fábrica de historias. Derechos, literatura, vida. Buenos Aires: FCE.

Changeux, J.P (2002). “Definición de la memoria biológica”, en Barret-Ducrocq, F. (ed.)¿Por qué recordar? Foro Internacional Memoria e Historia, UNESCO, 25/03/1998, La Sorbonne. Barcelona: Granica, 15-20.

Labov, W. (1972). Language in the inner city, Philadelphia: University of Pennsylvania Press.

Ricoeur, P. (2002). “Definición de historia desde un punto de vista filosófico", en Barret-Ducrocq, F. (ed.) ¿Por qué recordar?. Foro Internacional Memoria e Historia, UNESCO, 25/03/1998, La Sorbonne. Barcelona: Granica, 2428.

Romilly, de, J. (2002). "La historia entre la memoria individual y la memoria colectiva”, en Barret-Ducrocq, F. (ed.) (2002) ¿Por qué recordar?. Foro Internacional Memoria e Historia, UNESCO, 25/03/1998, La Sorbonne. Barcelona: Granica, 43-46.

Slobin, D.I. (1996) "Two ways to travel: Verbs of motion in English and Spanish". En: Shibatani, M. y S A. Thompson, S. (editors), Grammatical constructions: Their form and meaning. Oxford: Clarendon Press, 195219. 
Smorti, A. (2001): El pensamiento narrativo: construcción de historias y desarrollo del conocimiento social, trad. Ma Dolores Ramírez Almazán, Sevilla: Mergablum.

Webgrafía:

Rando, J. (2006). Pensamiento, en https://www.museojorgerando.org>el-ar... Acceso, 19/12/2017. 